\title{
Genome wide meta-analysis of cDNA datasets reveals new target gene signatures of colorectal cancer based on systems biology approach
}

\author{
Umair llyas $^{{ }^{*}}$, Shahiq uz Zaman ${ }^{1}$, Reem Altaf ${ }^{2}$, Humaira Nadeem² and Syed Aun Muhammad ${ }^{3}$
}

\begin{abstract}
Background: Colorectal cancer is known to be the most common type of cancer worldwide with high diseaserelated mortality. It is the third most common cancer in men and women and is the second major cause of death globally due to cancer. It is a complicated and fatal disease comprising of a group of molecular heterogeneous disorders.

Results: This study identifies the potential biomarkers of CRC through differentially expressed analysis, system biology, and proteomic analysis. Ten publicly available microarray datasets were analyzed and seven potential biomarkers were identified from the list of differentially expressed genes having a $p$ value $<0.05$. The expression profiling and the functional enrichment analysis revealed the role of these genes in cell communication, signal transduction, and immune response. The protein-protein interaction showed the functional association of the source genes (CTNNB1, NNMT, PTCH1, CALD1, CXCL14, CXCL8, and TNFAIP3) with the target proteins, such as AXIN, MAPK, IL6, STAT, APC, GSK3B, and SHH.

Conclusion: The integrated pathway analysis indicated the role of these genes in important physiological responses, such as cell cycle regulation, WNT, hedgehog, MAPK, and calcium signaling pathways during colorectal cancer. These pathways are involved in cell proliferation, chemotaxis, cellular growth, differentiation, tissue patterning, and cytokine production. The study shows the regulatory role of these genes in colorectal cancer and the pathways that can be effected after the dysregulation of these genes.
\end{abstract}

Keywords: Colorectal cancer, Microarrays, Functional genomics, PPI network, Biomarkers

\section{Background}

After breast and lung cancer, colorectal cancer (CRC) has been diagnosed to be the third most common malignancy. It is the fourth leading cause of death with 1.4 million cases and almost 694,000 deaths. CRC is the third

\footnotetext{
*Correspondence: umair.ilyas@riphah.edu.pk

${ }^{1}$ Department of Pharmaceutics, Faculty of Pharmaceutical Sciences,

Riphah International University, Islamabad 44000, Pakistan

Full list of author information is available at the end of the article
}

most common malignancy in males after prostate and lung cancer and second in females after breast cancer. The incidence rate of CRC has been rising in the developing countries due to westernization that is causing increased risk factors for CRC [1]. About $60 \%$ increase in the global burden of CRC, based on the demographic projections, is estimated to occur with 2.2 million new cases and 1.1 million deaths by 2030 . More than $25 \%$ of patients with colorectal cancer are diagnosed with metastatic disease. Therefore, for improved sensitivity and specificity of detection of CRC new biomarkers have 
been developed [2]. Numerous risk factors are known to be associated with the progression of CRC with $95 \%$ of cases having adenocarcinomas. This includes enhanced alcohol intake, reduced physical exercise, a poor diet plan that is rich in fats and poor in fibers, personal or familial history of polyps, age greater than 50 , and inflammatory bowel disease [3].

Following the development of colorectal carcinoma, the subsequent genetic and epigenetic alterations in specific oncogenes and/or tumor suppressor genes of gastrointestinal epithelial cells causes it to undergo cell proliferation and self-renewal, triggering the normal epithelium to be hyperproliferative mucosa. This results in a benign adenoma that eventually grows into carcinoma and in about 10 years becomes metastatic [4].

The normal epithelial cells of the gastrointestinal tract are arranged along a crypt-villus axis. The undifferentiated pool of colon stem cell and progenitor cells having the ability of self-renewal and pluripotency are found at the bottom of the crypt. These cells while moving along the axis undergo differentiation in all epithelial colon lineages. Whilst these cells arrive at the top of the axis which usually takes 14 days they result in apoptosis. Several proteins are known to be involved in the regulation of this process such as BMP, Wnt, and TGF- $\beta$ [4]. The onset of CRC has shown the involvement of various altered molecular signaling pathways that may result in the resistance to anti-tumor agents. These pathways include the $\mathrm{Wnt} / \mathrm{APC} / \beta$-catenin, transforming growth factor- $\beta$ (TGF)- $\beta /$ Smad, phosphoinositide 3-kinase (PI3K)/AKT/glycogen synthase kinase-3B and NF- $\kappa \beta$.

The diagnosis of CRC plays a pivotal role in the early prediction of CRC. If detected early it can be treated with surgery alone, however, in metastatic disease along with surgery chemotherapy is included. Presently, the prediction of CRC is based on the classification of the American Joint committee on Cancer (AJCC), TNM staging. But because each stage is a heterogeneous group of disease it is difficult to relate the TNM staging with prognosis. A more rapid and cheaper form of molecular characterization of cancer has become possible with the advancement of NGS technology. Most of the genetic biomarkers have gained a clinical value as a prognostic or therapeutic marker such as the MSI and the EGF signaling pathway [4].

To get a clear picture of the carcinogenesis, tumor growth and metastasis of colorectal cancer, the microarray analysis has been proved useful to gather information on thousands of genes at a time. The genomic alterations occurring in colorectal cancer can be identified by microarray analysis which can help in the diagnosis, characterization, and treatment of colorectal cancer [5]. However, certain challenges are still faced in the application of microarray assays according to some studies. One approach to overcome such challenges is to utilize the online Gene Expression Omnibus (GEO) database. This database can assist in increasing the size of the sample, statistical power and sample heterogeneity [6-8].

The aim of this study is to screen out significant CRC associated genes that can act as candidate biomarkers to detect early cancer and to elucidate the pathogenesis of CRC. The differential expression analysis of ten microarray datasets was performed to identify the candidate genes based on significant scoring function. The expression profiling of these genes was also performed to determine the expression patterns of these potential markers in several tissues. Cluster analysis and Functional enrichment analysis was employed to confirm the function and association of shortlisted genes in causing CRC. The protein-protein interaction and pathway analysis confirmed the association of candidate genes with colorectal cancer and the regulation of Wnt, NF- $\mathrm{k} \beta$, and MAPK. The search for new predictive, diagnostic and prognostic biomarkers in colorectal cancer is of great importance and has become the goal of biomedical research on CRC. The study will aid in the biomarker discovery by getting valuable insights through studying these molecular networks that can be used in public datasets for better outcomes in other diseases as well.

\section{Methods}

\section{Accession of gene expression data}

The aim of this study was to identify potential targets for colorectal cancer. The gene expression datasets of colorectal cancer were accessed from the Gene Expression Omnibus database under two screening conditions (organism: Homo sapiens, experiment type: expression profiling by an array). Each dataset comprises of GEO accession number, platform, sample type, number of samples and gene expression data. The array platform used was Affymetrix GeneChip Human Genome U133 Plus 2.0 Array (CDF: Hs133P_Hs_ENST, version 10) (Affymetrix, Inc., Santa Clara, CA, 95051, USA, Technology: in situ oligonucleotides). In order to detect the gene expression, the array platform and the annotation information (hgu133plus2) of probes were used. Computational analysis was performed using $\mathrm{R}$ and BioConductor packages containing AffyQCReport, Affy, Annotate, AnnotationDbi, Limma, Biobase, AffyRNADegradation, hgu133plus2cdf, and hgu133a2cdf.

\section{Preprocessing and differential expression analysis of microarray datasets}

The phenodata files were prepared for each dataset in a recognizable format [9]. The normalization of the data was done using Bioconductor "ArrayQuality Metrics" 
package on $\mathrm{R}$ version 3.1.3 to a median expression level of each gene [10-12]. This was done to compare the microarray data sets. The background correction for perfect matches (PM) and mismatches (MM) was performed by the Robust Multi-array Analysis (RMA) in order to remove local noise and artifacts [9]. Perfect matches (PM) and mismatches (MM) was calculated using the following equation.

$$
P M_{i j k}=B G_{i j k}+S_{i j k} .
$$

where, PM is a perfect match, Background (BG) caused by optical noise and non-specific binding (S); ijk is the signal for probe $j$ of probe set $k$ on array $i$.

$$
\begin{aligned}
& B G\left(P M_{i j k}\right)=E\left[S_{i j k} \mid P M_{i j k}\right]>0 . \\
& S_{i j k} \sim \operatorname{Exp}\left(\lambda_{i j k}\right) B G_{i j k} \sim N\left(\beta_{i}, \sigma^{2}\right) .
\end{aligned}
$$

The background (BG) and the signal expression (E) forms the PM-data. The dataset normalized to median level expression was analyzed by the "Array Quality Metrics" package of Bioconductor software [10-12]. Expression value having a $p$-value $<0.15$ was considered marginal log transformation. For each dataset, the genegene covariance matrix was calculated across all array (54675 Affyids) using the following formula.

$$
X_{\text {norm }}=F 2^{-1}(F 1(x)) .
$$

where $F 1$ and $F 2$ are distribution functions of the actual and reference chips, respectively.

To attain the summary of intensities the RMA-algorithm was used to calculate the averages between probes in a probe set.

The degradation analysis to measure the quality of RNA in these datasets, AffyRNADegradation package of Bioconductor was used (Affymetrix, 1999, 2001). The pairwise comparison was done to identify the DEGs in each dataset and for multiple testing correction Benjamini-Hochberg method was employed. The differentially expressed genes were shortlisted along with measurement of quality weights. The shortlisted genes were ranked according to their $p$ values and the resulting scores. Significant cut off values was set to calculate the moderated statistics with $p$-value $\leq 0.05, \mathrm{FDR}<0.05$ (false discovery rate), absolute $\log$ fold change $(\operatorname{logFC})>1$ and FDR $<0.05$ (false discovery rate) [13].

\section{Curation of CRC-related genes}

The shortlisted DEGs were further screened for colorectal associated genes using diverse data source including PubMed, MeSH, OMIM, and PMC database to filter significant disease specific genes. The cluster analysis [14] was performed based on expression values in each dataset of CRC-related differential expressed genes in order to identify the variations in gene expression levels between treated and untreated replicates using CIMminer tool [15].

\section{Functional enrichment analysis}

In order to understand the biological functions of these CRC related genes the Gene ontology, functional annotation and pathway enrichment analysis $[16,17]$ was performed. The web-based tools used for this purpose were DAVID (Database for Annotation Visualization and Integrated Discovery) [18] and FunRich Annotation tools [19].

\section{Protein-protein interaction network}

The topology and functional protein interactions are useful to analyze the biological and pathological conditions of a specific disease. The protein-protein interaction helps in identifying these features and the functional relationship of such proteins can be interpreted through genomic associations $[17,20]$. The PPI network shows the interaction of each protein with a number of other genes with biological or molecular functions having different activity in the pathological state as compared to normal [21]. Proteins that interacted with each other during colorectal cancer were evaluated from STRING (Search Tool for the Retrieval of Interacting Genes/Proteins) [21] and HAPPI databases (Human Annotated and Predicted Protein Interaction) databases [22] with a confidence score of 0.999. Cytoscape software (version 3.2.1) was used to visualize the molecular and network interaction to identify the role of seeder and target genes in CRC [23]. The network showed the role of each target gene signatures that interacted with CRC associated source genes in colorectal cancer. The role was determined by mapping the target gene with seeder genes using, OMIM, MeSH, and PMC databases. The gene mapping determines the potential colorectal related gene signatures to be functionally related whose dysregulation causes a disease phenotype. The total number of target genes interacted with each source protein was calculated. A molecular sub-network of those genes that were associated with pathways of interest causing colorectal cancer was constructed. The topological network properties were calculated using Network Analyzer in Cytoscape [24].

\section{Integrated pathway modeling}

The integrated and metabolic networks of CRC-related source genes were analyzed and the Co-relation between test genes was observed. To recognize the underlying 
pathways involved in the progression of CRC the pathway analysis was performed which could help in identifying the biomarkers of this disease. The curation and mapping of candidate biomarkers were done using KEGG (Kyoto Encyclopedia of Genes and Genomes) [25], Reactome and Wiki pathways. PathVisio3tool was used to reconstruct the cellular and signaling pathways of potential biomarkers [26] and the potential mechanism of each marker in the pathway was studied based on the pieces of evidence available in literature and databases. For cross-verifications, we used TCGA and the Human Protein Atlas databases and analyzed the expression level of ranked DEGs in colorectal cancer.

\section{Results}

\section{Microarray analysis and normalization}

Ten datasets were downloaded from online GEO database with .CEL format related to CRC. The size of an array of AffyBatch object comprised of $1164 \times 1164$ and $732 \times 732$ features with related Affyids (Table 1). In order to avoid the systematic variation, the quantile normalization was used for background correction and normalization. The probe level data obtained after normalization shows the quality of the individual array of each dataset in the MA plots (Fig. 1). The computation of genegene covariance matrix across all arrays was performed by ignoring the missing values in each dataset and to assure they were on a similar scale to log-transform the arrays. In each probe sets, the probes were arranged by location relative to the $5^{\prime}$ end of the targeted RNA molecule. The severity of RNA-degradation and significance level was presented by function plotAffyRNAdeg (Fig. 2) and a single summary statistic for each array in the batch was produced by the function summary of AffyRNAdeg (Additional file 1: Table S1). The list of databases, tools, and software used in this study are available in (Additional file 1: Table S2).

\section{Identification and screening of differentially expressed genes}

About 50 DEGs in each microarray dataset were identified by pairwise comparison between biologically comparable groups. From these 50 DEGs, the top 20 genes in each dataset were ranked and selected based on FDR $(<0.05), p$-value $(\leq 0.05)$ and $\operatorname{logFC}(>1)$ parameters. And from these 20 genes, seven common genes of each dataset were identified as the potential biomarker candidate (Additional file 1: Table S3).

\section{Data mining and cluster analysis}

The seven significant colorectal cancer associated genes shortlisted from the differentially expressed genes were CALD1, CTNNB1, CXCL14, PTCH1, CXCL8, TNFAIP3, and NNMT after mapping with PubMed, OMIM, MeSH, and PMC databases. The role of sorted genes in colorectal cancer was curated and counted (Table 2).

The genetic expression of colorectal cancer cell samples showed a clear difference between the treated and untreated groups (Fig. 3).

\section{Gene enrichment analysis}

Significant enrichment was obvious in 5 downregulated and 2 upregulated genes. The clinical phenotypes associated with the dysregulation of these genes are pilomatrixoma, congenital lung cyst and ovarian fibromata (Fig. 4a). The biological processes are related to cell communication, signal transduction, immune response, energy, metabolism and cell growth and maintenance (Fig. 4b).

\section{Gene network analysis}

In PPI, a total of 233 nodes and 134 edges were retrieved from STRING [21] and HAPPI database [22] with a confidence score of 0.99 . The database showed the interaction of CRC-associated genes with potential other genes that were contributing to a disease phenotype. The network was categorized into three neighborhoods: light pink and red nodes indicate the CRC-associated potential biomarkers while the remaining blue nodes represent the other target proteins. The potential biomarkers were found to functionally interact with other biologically essential target proteins. Some of them are, APC, IL6, MAPK1, NFkb1 and SHH (Fig. 5). The source protein CTNNB1 was shown to be interacting with APC and NNMT showed interaction with CDK38 and STAT3. Similarly, CALD1 is associated with MAPK1 while, PTCH1 shows interaction with a family of hedgehog proteins $\mathrm{SHH}, \mathrm{IHH}$ and $\mathrm{DHH}$ with clinical phenotypes. The network analyzer was used to classify and improve the network performance and to interpret the topological properties of the network. The disease gene mapping of target genes using CTD showed that more than 50 genes have a functional relation with the source/seeder genes in CRC (Fig. 5).

\section{Pathway modeling}

The source genes identified were further studied to evaluate the molecular mechanism of these genes in CRC. The network generated after reconstruction showed that several pathways were involved in the pathogenesis of colorectal cancer. Along with the Wnt pathway and the canonical pathway other pathways, the MAPK pathway, Calcium signaling pathway, metabolic pathway and RIGlike 1 receptor pathway have also shown a connection with colorectal cancer (Fig. 6). The gene ontology of these pathways is associated with cell proliferation, chemotaxis, stem cell maintenance, and apoptosis. Therefore, 
Table 1 List of CDNA datasets

\begin{tabular}{|c|c|c|c|c|c|c|c|c|}
\hline Accession No. & Total samples & Tissues & Species & $\begin{array}{l}\text { Conditions/ } \\
\text { type }\end{array}$ & Platform & Size of arrays & AffylDs & References \\
\hline GSE 9412 & 6 & $\begin{array}{l}\text { Colorectal } \\
\text { cancer }\end{array}$ & Homo sapiens & $\begin{array}{l}\text { Sensitive vs } \\
\text { resistant }\end{array}$ & $\begin{array}{l}\text { GPL571 [HG- } \\
\text { U133A_2] } \\
\text { Affym- } \\
\text { etrix Human } \\
\text { Genome } \\
\text { U133A 2.0 } \\
\text { Array }\end{array}$ & $\begin{array}{l}732 \times 732 \text { fea- } \\
\text { tures }\end{array}$ & 22277 & Selga et al. [34] \\
\hline GSE 11440 & 6 & Colon & Homo sapiens & $\begin{array}{c}\text { Sensitive vs } \\
\text { resistant }\end{array}$ & $\begin{array}{l}\text { GPL570 [HG- } \\
\text { U133_Plus_2] } \\
\text { U133Plus 2.0 } \\
\text { Array }\end{array}$ & $\begin{array}{c}1164 \times 1164 \\
\text { features }\end{array}$ & 54675 & Mencia et al. [35] \\
\hline GSE14773 & 8 & Colon & Homo sapiens & $\begin{array}{l}\text { Control vs } \\
\text { treated }\end{array}$ & $\begin{array}{l}\text { GPL570 [HG- } \\
\text { U133_Plus_2] } \\
\text { U133Plus 2.0 } \\
\text { Array }\end{array}$ & $\begin{array}{c}1164 \times 1164 \\
\text { features }\end{array}$ & 54675 & Hwang et al. [36] \\
\hline GSE 15102 & 8 & Colon & Homo sapiens & $\begin{array}{l}\text { Control vs } \\
\text { treated }\end{array}$ & $\begin{array}{l}\text { GPL571 [HG- } \\
\text { U133A_2] } \\
\text { Affym- } \\
\text { etrix Human } \\
\text { Genome } \\
\text { U133A 2.0 } \\
\text { Array }\end{array}$ & $\begin{array}{l}732 \times 732 \text { fea- } \\
\text { tures }\end{array}$ & 22277 & Sagiv et al. [37] \\
\hline GSE 18560 & 12 & Colorectal & Homo sapiens & $\begin{array}{l}\text { Control vs } \\
\text { treated }\end{array}$ & $\begin{array}{l}\text { GPL570 [HG- } \\
\text { U133_Plus_2] } \\
\text { Affym- } \\
\text { etrix Human } \\
\text { Genome U133 } \\
\text { Plus 2.0 Array }\end{array}$ & $\begin{array}{c}1164 \times 1164 \\
\text { features }\end{array}$ & 54675 & Selga et al. [34] \\
\hline GSE 27157 & 10 & $\begin{array}{l}\text { Colorectal } \\
\text { cancer }\end{array}$ & Homo sapiens & $\begin{array}{l}\text { p53 wild vs. } \\
\text { tumor sam- } \\
\text { ples }\end{array}$ & $\begin{array}{l}\text { GPL570 [HG- } \\
\text { U133_Plus_2] } \\
\text { Affym- } \\
\text { etrix Human } \\
\text { Genome U133 } \\
\text { Plus 2.0 Array }\end{array}$ & $\begin{array}{c}1164 \times 1164 \\
\text { features }\end{array}$ & 54675 & $\begin{array}{l}\text { Katkoori et al. } \\
\text { [38] }\end{array}$ \\
\hline GSE 29316 & 6 & Colon fibroblast & Homo sapiens & $\begin{array}{l}\text { Control vs } \\
\text { treated }\end{array}$ & $\begin{array}{l}\text { GPL570 [HG- } \\
\text { U133_Plus_2] } \\
\text { Affym- } \\
\text { etrix Human } \\
\text { Genome U133 } \\
\text { Plus 2.0 Array }\end{array}$ & $\begin{array}{c}1164 \times 1164 \\
\text { features }\end{array}$ & 54675 & Chen et al. [39] \\
\hline GSE 32323 & 44 & $\begin{array}{l}\text { Colorectal } \\
\text { cancer }\end{array}$ & Homo sapiens & $\begin{array}{l}\text { Control vs } \\
\text { Treated }\end{array}$ & $\begin{array}{l}\text { GPL570 [HG- } \\
\text { U133_Plus_2] } \\
\text { Affym- } \\
\text { etrix Human } \\
\text { Genome U133 } \\
\text { Plus 2.0 Array }\end{array}$ & $\begin{array}{c}1164 \times 1164 \\
\text { features }\end{array}$ & 54675 & Khamas et al. [40] \\
\hline GSE 35144 & 64 & Colorect cancer & Homo sapiens & Case vs control & $\begin{array}{l}\text { GPL570 [HG- } \\
\text { U133_Plus_2] } \\
\text { Affym- } \\
\text { etrix Human } \\
\text { Genome U133 } \\
\text { Plus 2.0 Array }\end{array}$ & $\begin{array}{c}1164 \times 1164 \\
\text { features }\end{array}$ & 54675 & Uronis et al. [41] \\
\hline GSE 55624 & 18 & $\begin{array}{l}\text { Colorectal } \\
\text { cancer }\end{array}$ & Homo sapiens & $\begin{array}{c}\text { Control vs } \\
\text { treated }\end{array}$ & $\begin{array}{l}\text { GPL570 [HG- } \\
\text { U133_Plus_2] } \\
\text { Affym- } \\
\text { etrix Human } \\
\text { Genome U133 } \\
\text { Plus 2.0 Array }\end{array}$ & $\begin{array}{c}1164 \times 1164 \\
\text { features }\end{array}$ & 54675 & $\begin{array}{l}\text { Schoumacher } \\
\text { et al. [42] }\end{array}$ \\
\hline
\end{tabular}



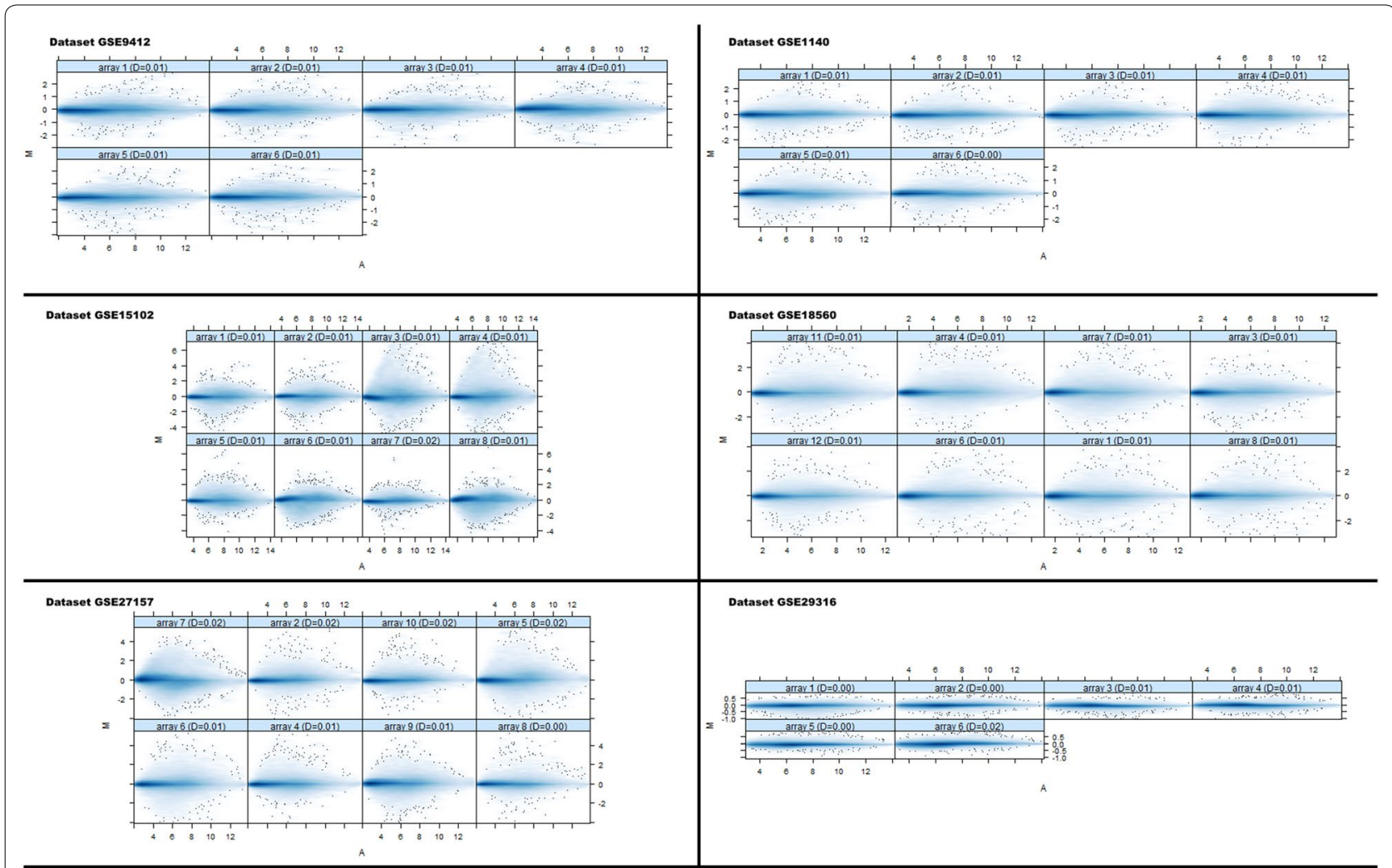

Dataset GSE29316
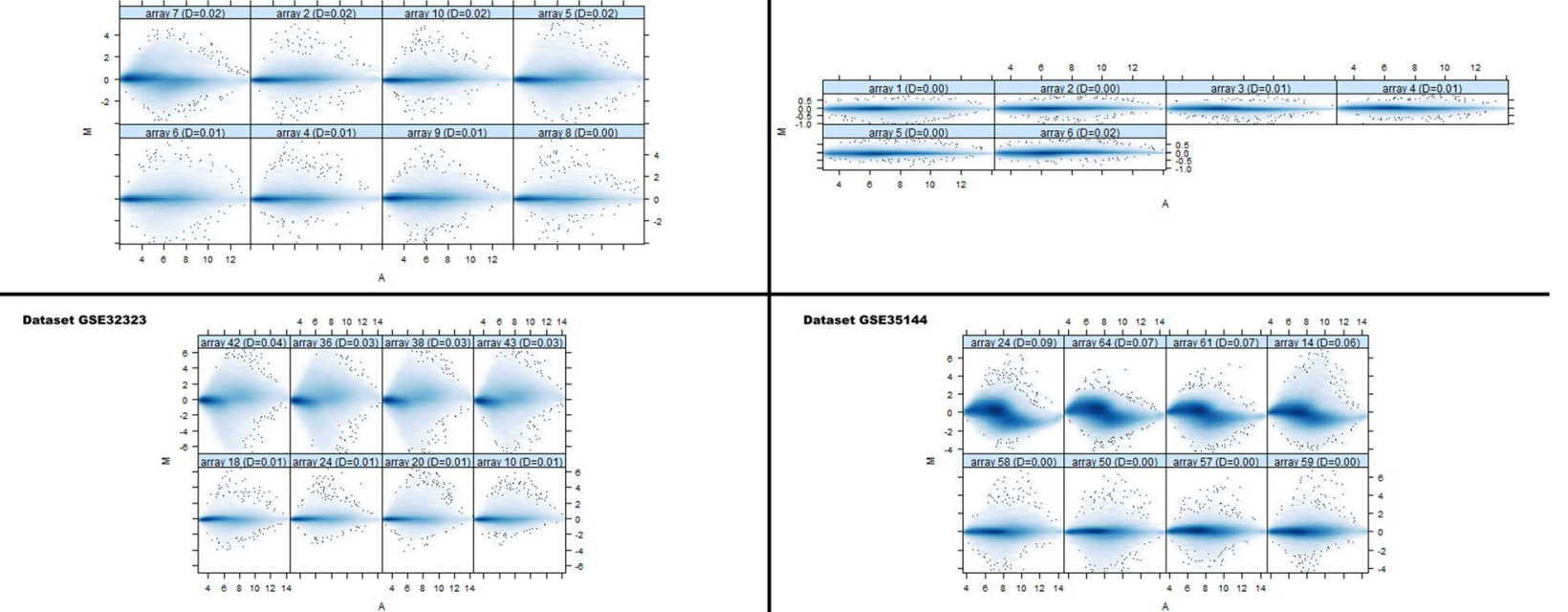

Dataset GSE35144
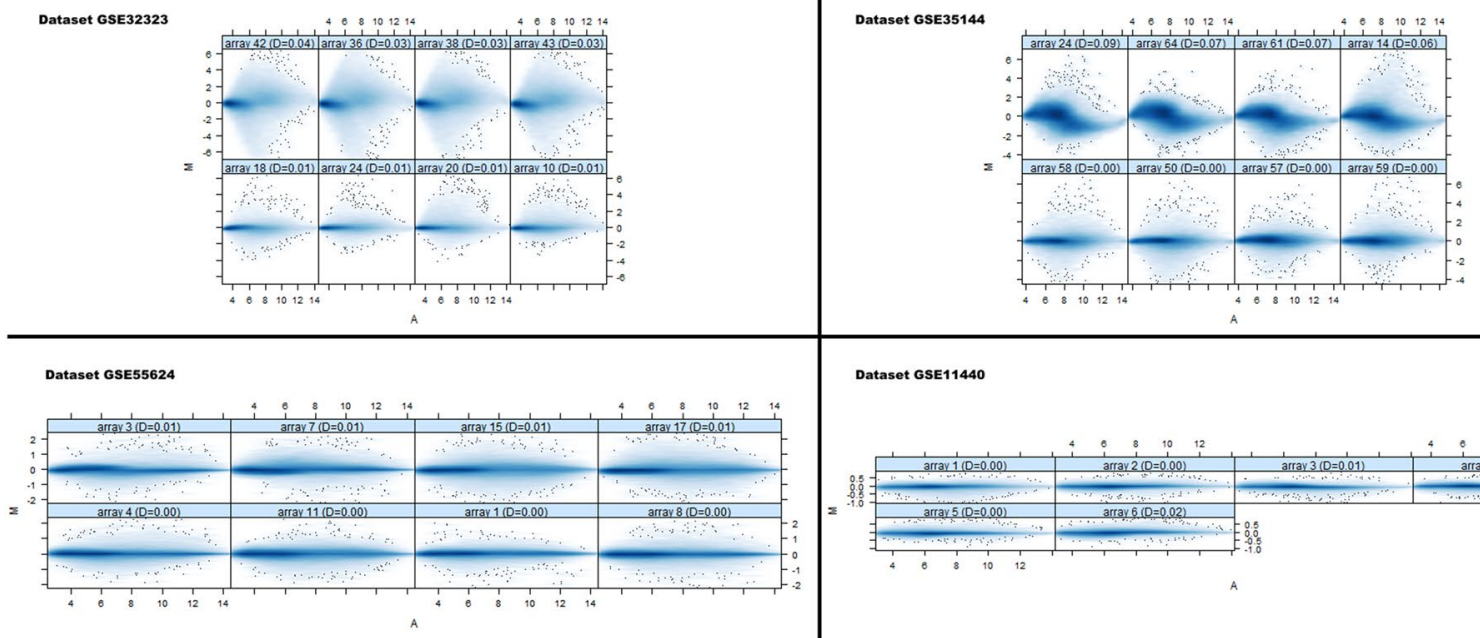

Dataset GSE11440

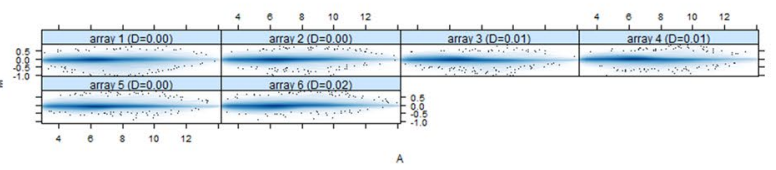

Fig. 1 MA plots of an individual quality array after normalization. $M$ and $A$ is specified as $M=\log _{2}\left(\left.\right|_{1}\right)-\log _{2}\left(I_{2}\right), A=1 / 2\left(\log _{2}\left(I_{1}\right)-\log _{2}\left(I_{2}\right)\right)$, where $I_{1}$ is the intensity of the array studied, and $I_{2}$ is the intensity of a "pseudo"-array that consists of the median across arrays". Normally, the mass of distribution in the MA plot is expected to be concentrated along the $M=0$ axis with no trend in $M$ as a function of $A$

the progression of CRC is related to the overexpression of genes that leads to cell proliferation and anti-apoptosis and downregulation of genes that inhibit the proliferation and cellular differentiation of cells. The association of differentially expressed genes with colorectal cancer were cross-referenced by TCGA and the Human Protein Atlas. The median expression level of interactive gene signatures and source DEGs is significant in cases as compared to control. The interactive survival scatter plot (Fig. 7) indicates the expression of these DEGs is favorable in colorectal cancer. The pathways and pathological analysis showed that the proteins level is linked with cancer. These interactive survival scatter plots indicated the consequence of RNA and protein levels on clinical 


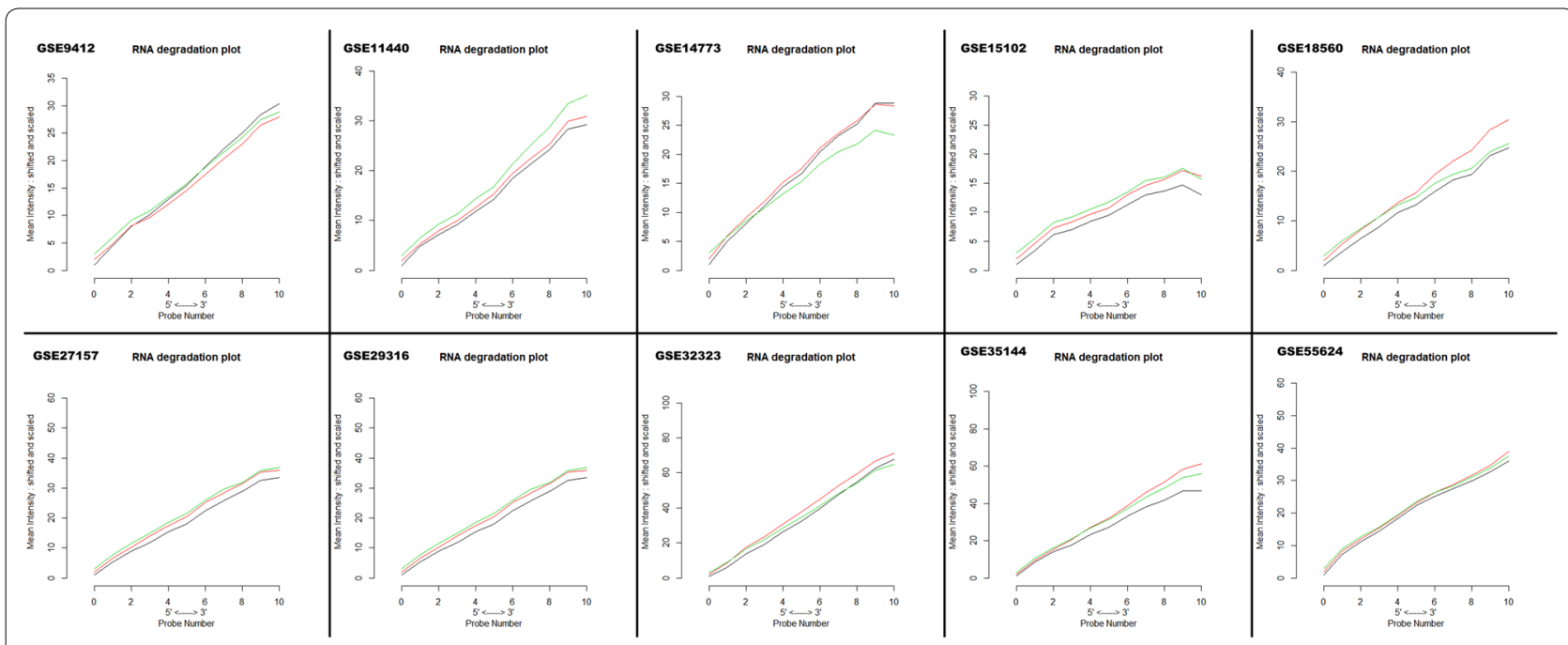

Fig. 2 RNA degradation plot of each dataset produced by plot AffyRNAdeg showing $5^{\prime}$ to $3^{\prime}$ trend to evaluate the severity of RNA degradation and significance level

Table 2 The differentially expressed CRC-associated genes curated from PubMed

\begin{tabular}{|c|c|c|c|c|c|c|}
\hline S.NO. & Probe ID & Gene ID & Uniprot_ID & PubMed Count & Protein name & Reference links \\
\hline 1. & 202237_at & NNMT & NNMT_HUMAN & 4 & $\begin{array}{l}\text { NNMT Homo sapiens nicotinamide } \\
\text { N-methyltransferase }\end{array}$ & $\begin{array}{l}\text { https://www.ncbi.nlm.nih.gov/ } \\
\text { pubmed/?term=\%22NNM } \\
\text { T\%22+AND+\%22COLORECT } \\
\text { AL+CANCER\%22 }\end{array}$ \\
\hline 2. & 212077_at & CALD1 & CALD1_HUMAN & 5 & Caldesmon 1 & $\begin{array}{l}\text { https://www.ncbi. } \\
\text { nlm.nih.gov/pubme } \\
\text { d/?term=\%22+CALD1 } \\
\text { \%22+AND+\%22COLORECT } \\
\text { AL+CANCER\%22 }\end{array}$ \\
\hline 3. & 201533_at & CTNNB1 & CTNB1_HUMAN & 506 & CTNNB1 Homo sapiens catenin beta 1 & $\begin{array}{l}\text { https://www.ncbi. } \\
\text { nlm.nih.gov/pubme } \\
\text { d/?term=\%22+CTNNB } \\
\text { 1\%22+AND+\%22COLORECT } \\
\text { AL+CANCER\%22 }\end{array}$ \\
\hline 4. & 222484_s_at & CXCL14 & CXL14_HUMAN & 3 & C-X-C motif chemokine ligand 14 & $\begin{array}{l}\text { https://www.ncbi. } \\
\text { nlm.nih.gov/pubme } \\
\text { d/?term=\%22+CXCL1 } \\
\text { 4+\%22+AND+\%22COL } \\
\text { ORECTAL+CANCER\%22 }\end{array}$ \\
\hline 5. & 209815_at & PTCH1 & PTC1_HUMAN & 15 & Patched 1 & $\begin{array}{l}\text { https://www.ncbi. } \\
\text { nlm.nih.gov/pubme } \\
\text { d/?term=\%22+PTCH1 } \\
\text { +\%22+AND+\%22COL } \\
\text { ORECTAL+CANCER\%22 }\end{array}$ \\
\hline 6. & 202644_s_at & TNFAIP3 & TNAP3_HUMAN & 26 & TNF alpha induced protein 3 & $\begin{array}{l}\text { https://www.ncbi.nlm.nih.gov/ } \\
\text { pubmed/?term=\%22+TNFAl } \\
\text { P3\%22+AND+\%22COL } \\
\text { ORECTAL+CANCER\%22 }\end{array}$ \\
\hline 7. & 202859_x_at & CXCL8 & & 5 & C-X-C motif chemokine ligand 8 & $\begin{array}{l}\text { https://www.ncbi. } \\
\text { nlm.nih.gov/pubme } \\
\text { d/?term=\%22+CXCL8 } \\
\text { +\%22+AND+\%22COL } \\
\text { ORECTAL+CANCER\%22 }\end{array}$ \\
\hline
\end{tabular}




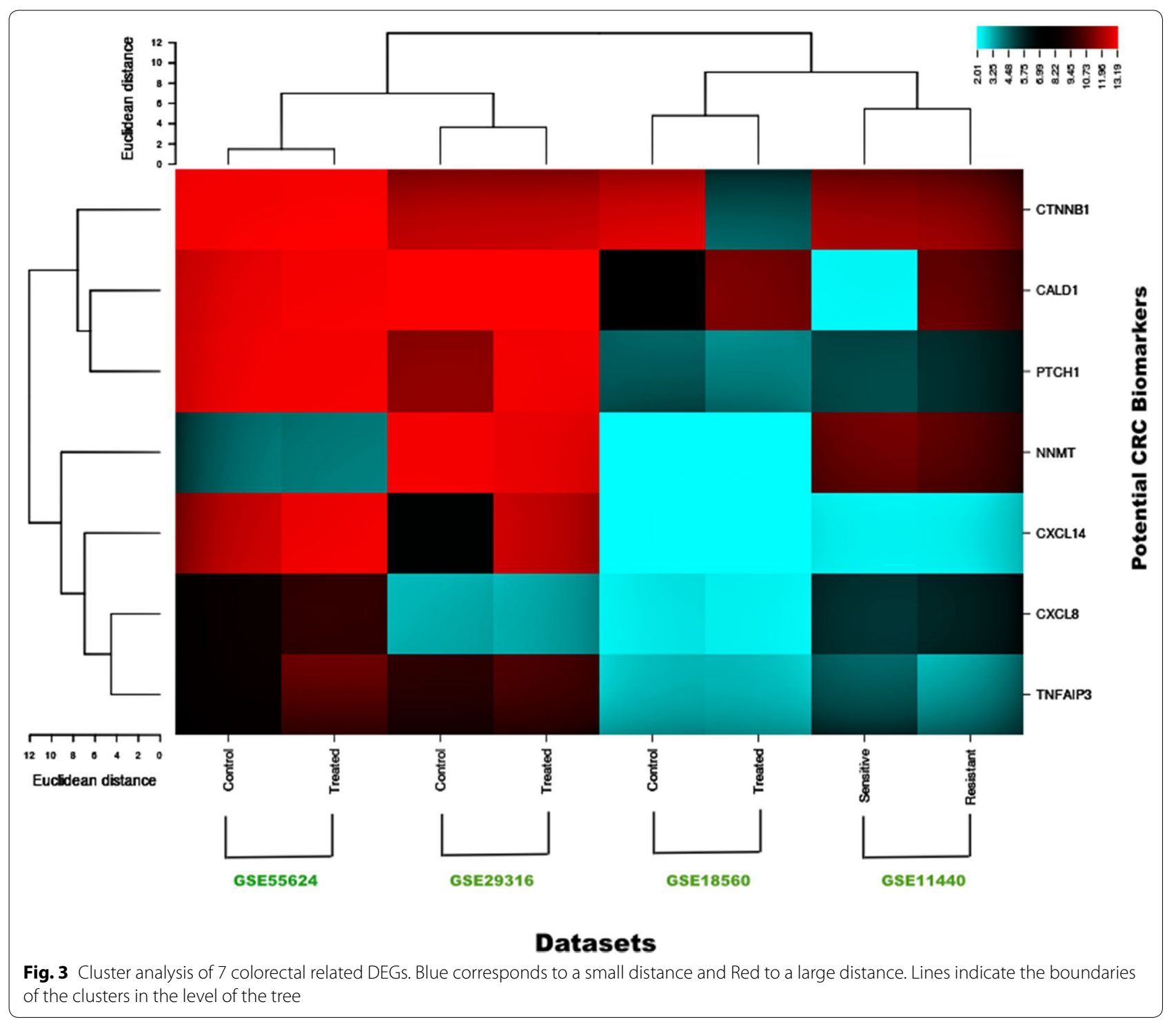

survival. The results showed that individual tumor gene expression patterns differed greatly and could surpass the variability between different types of cancer. Lower patient survival was usually associated with over-expression of genes in mitosis and cell growth and down-regulation of genes involved in cellular differentiation. This data enables the generation of metabolic models in a customized genome scale for cancer patients to recognize important genes of tumor growth.

\section{Discussion}

In this study, the DEG for colorectal cancer were identified and their GO studies were performed to analyze their functions. The gene network was established and the pathways through which these DEGs were deregulated were also identified. The study provides a new platform for the determination of pathogenesis of colorectal cancer.

The differential analysis revealed 7 differentially expressed signature genes out of 50 DEGs on the basis of physicochemical and functional analysis $(p<0.05)$ that showed involvement in the progression of colorectal cancer. These signature genes are CALD1, CTNNB1, CXCL14, PTCH1, CXCL8, TNFAIP3, and NNMT. The functional role of these genes in colorectal cancer and their dysregulation has been extensively studied [27-30]. Out of seven genes, two genes were upregulated while the rest showed downregulation. The GO study revealed that following functional categories were enriched among dysregulated genes; response to molecule of bacterial 

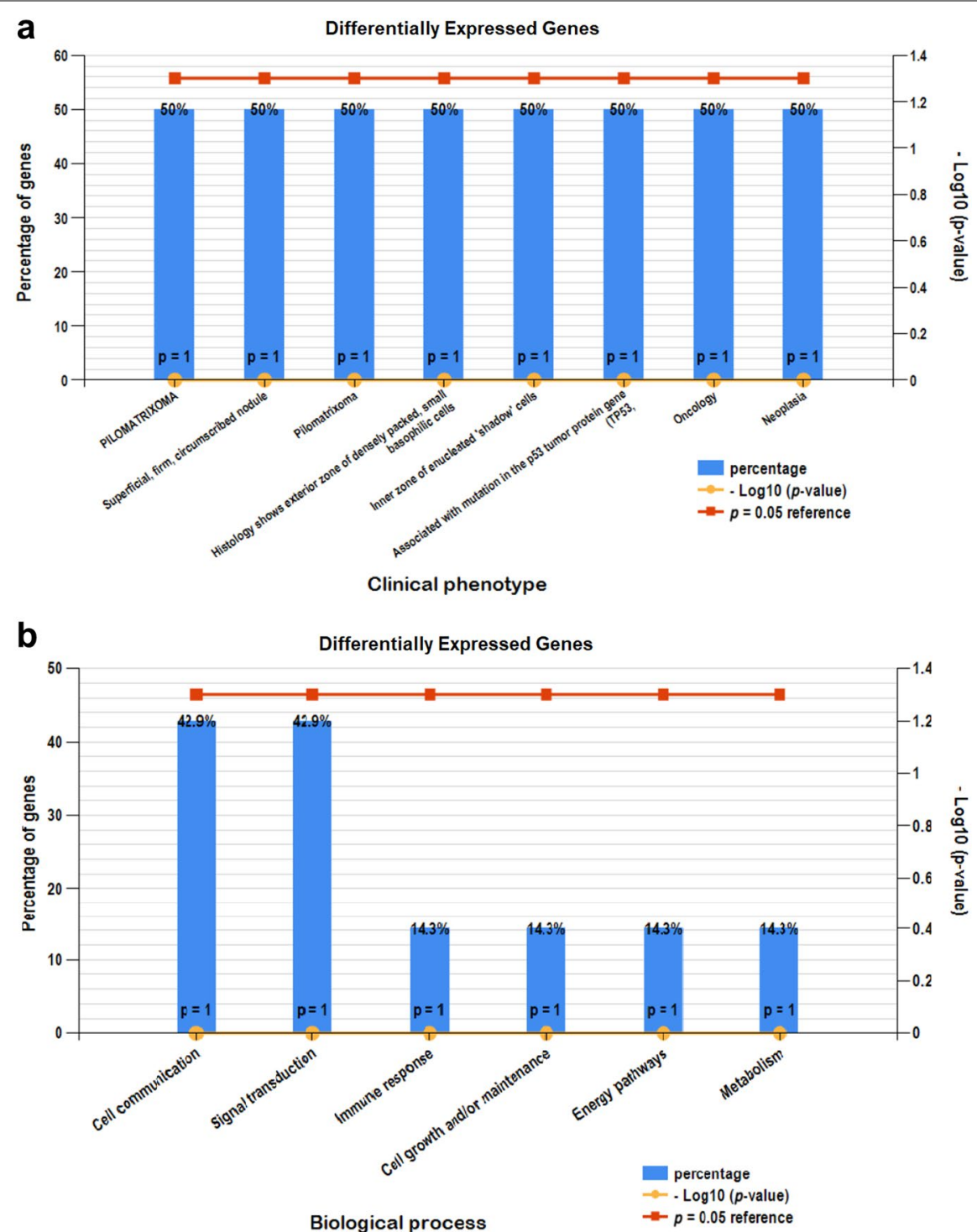

Fig. 4 a Clinical phenotypes analysis of CRC related DEGs. b Biological pathway analysis using FunRich tool

origin, response to a drug, cellular response to lipopolysaccharide, chemotaxis, movement of a cell or subcellular component and branching involved in ureteric bud morphogenesis. These genes showed a link to important biological pathways such as, methylation, beta-catenin signaling cascade and wnt canonical pathway. The dysregulation of these genes can cause Pilomatrixoma, congenital lung cyst, and other clinical phenotypes.

The network study showed the functional association of possible biomarker candidates with other interacting protein targets such as APC, AXIN, MAPK, TRAF, GLI, and $\mathrm{SHH}$. The mutation of APC genes has been shown to be present in $90 \%$ of the patients with human CRC that interacts with CTNNB1 in the Wnt pathway. More than
80 target genes showed a connection with the source genes in causing colorectal cancer. The mutation of Kras genes also plays a pivotal role in the progression of colorectal cancer during the early adenoma stage. The cross talk between the wnt/ $\beta$-catenin and RAS-ERK pathway exist and the interaction between the two pathways during the various stages of colorectal cancer the combined mutations of which lead to malignant transformation of CRC [31]. The interaction between the NNMT and the MAP/ERK pathway has also been under investigation reporting the cell survival, apoptosis and cell cycle progression of cancer tissues. The overexpression of NNMT has indicated the acceleration of cell proliferation by regulating the energy metabolism in CRC tissues and by its 


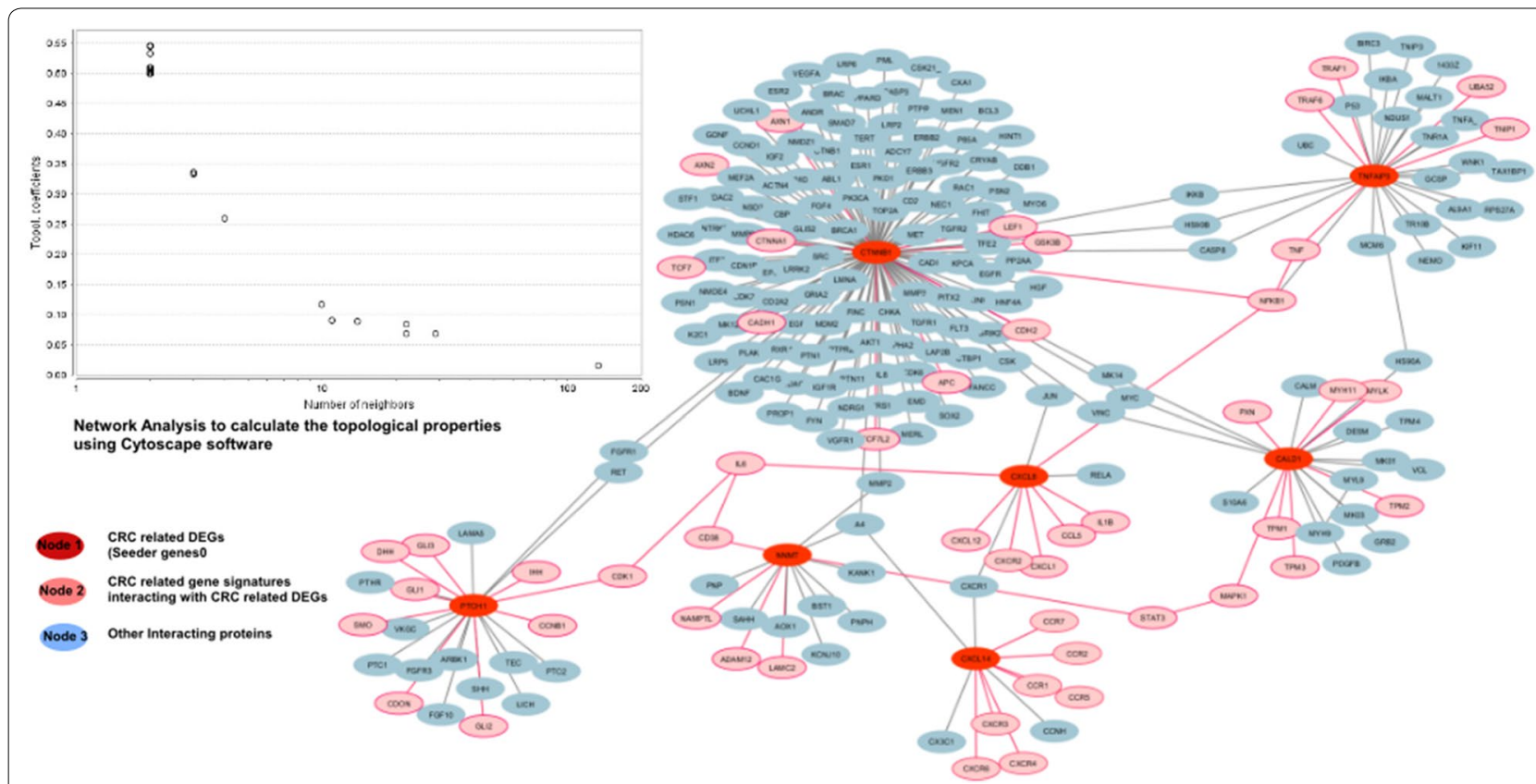

Fig. 5 A genetic network of a total number of gene signatures associated with CRC differentially expressed seeder genes. Red nodes represent CRC seeder genes, blue nodes showing signature genes associated with seeder genes having no role in CRC while pink nodes represent gene signatures associated with seeder genes having a role in CRC

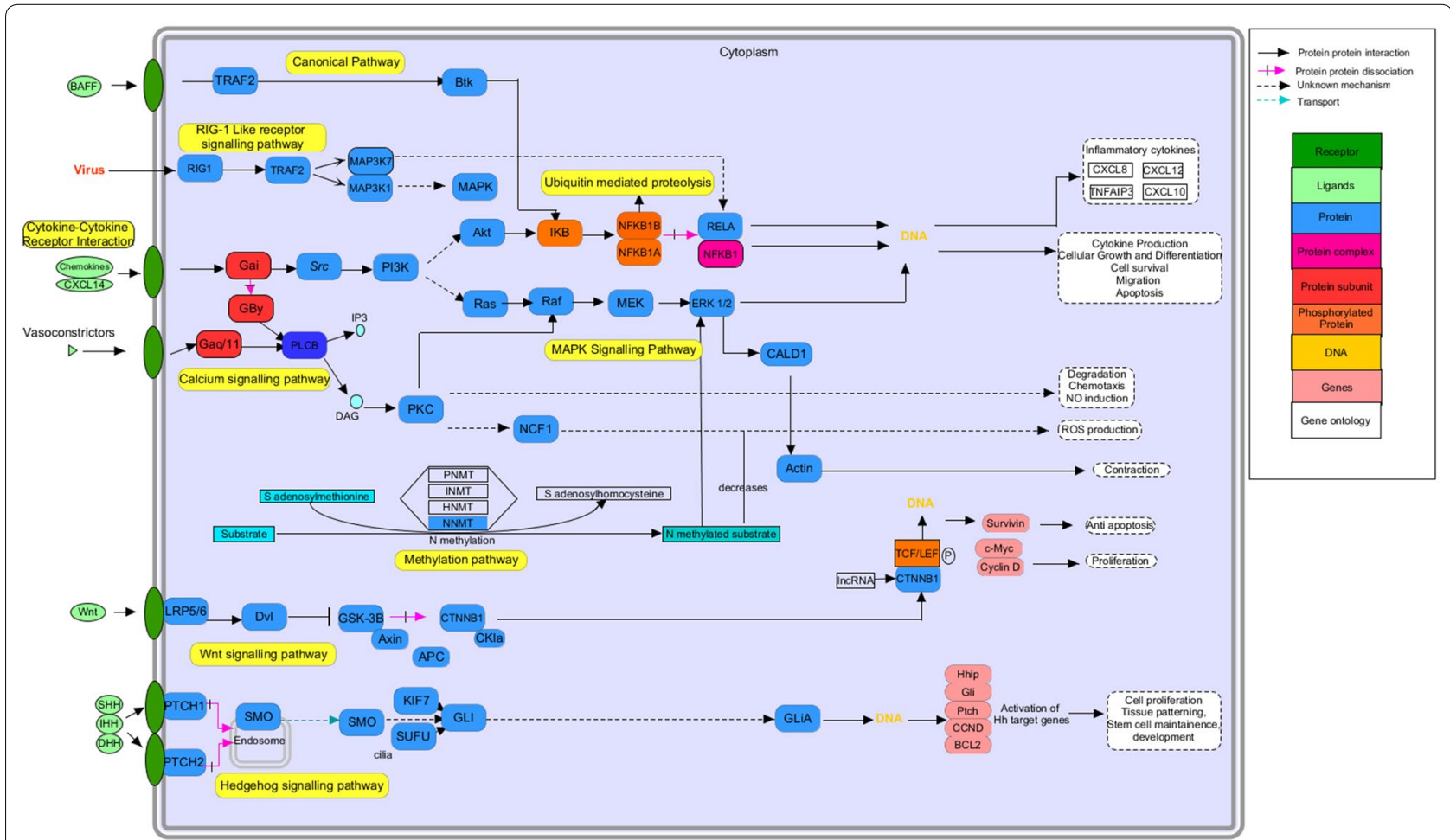

Fig. 6 Pathway modeling. Integrated genome to phenome scale signaling pathways involved in CRC. KEGG pathway was used to map the gene signatures for signaling and metabolic reconstruction 

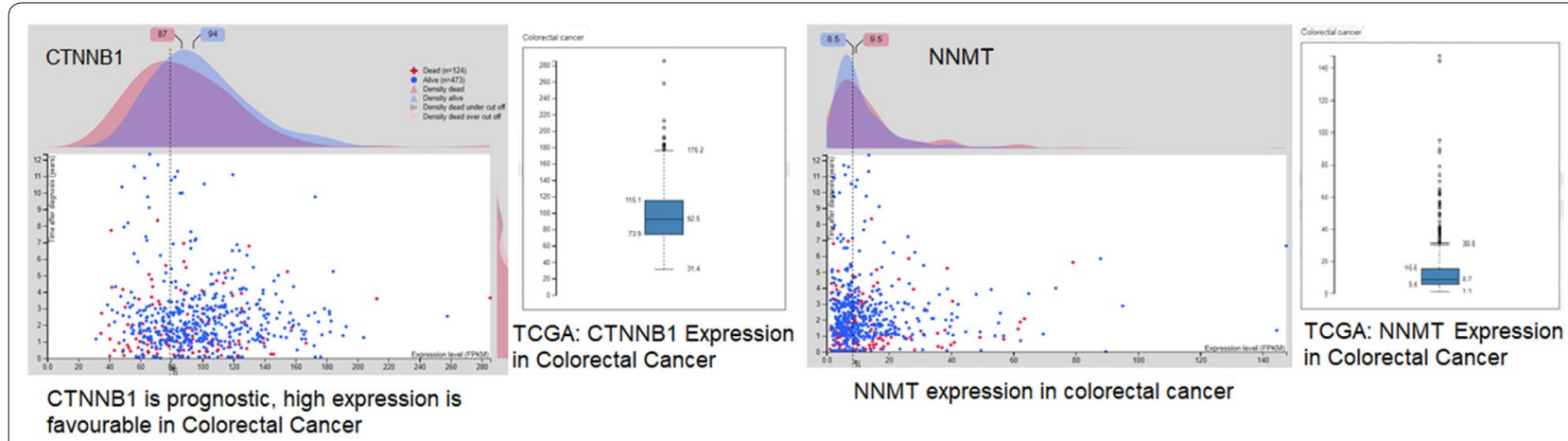
favourable in Colorectal Cancer

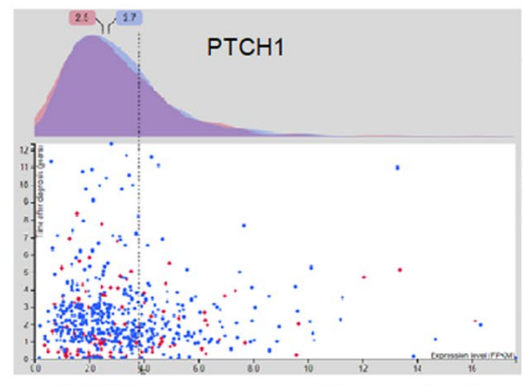

$\mathrm{PTCH} 1$ is prognostic, high expression is
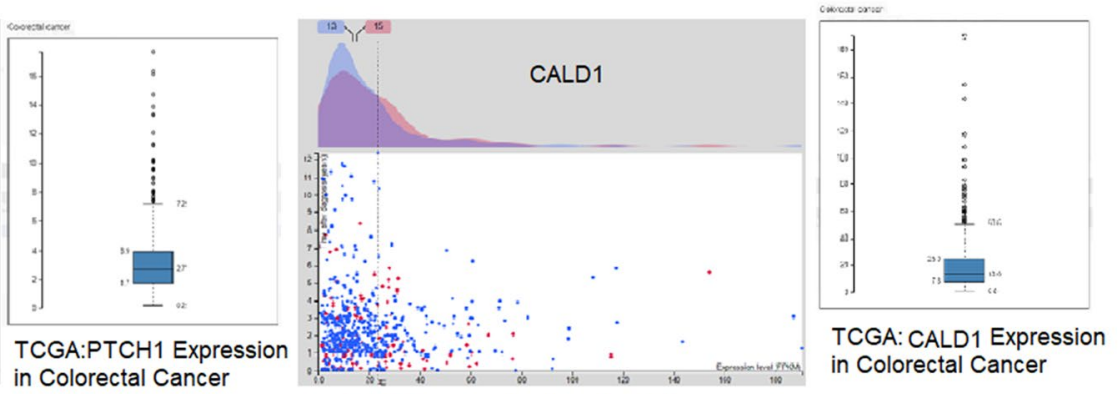

favourable in Colorectal Cancer

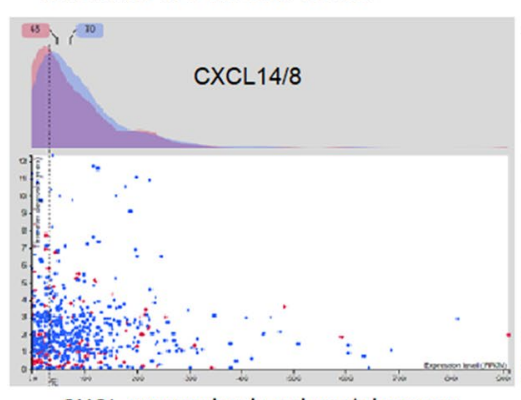

CXCL expression in colorectal cancer

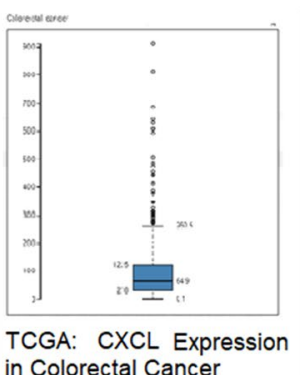

in Colorectal Cancer

Fig. 7 Interactive scatter plot indicates the expression-level of differentially expressed genes in colorectal cancer. These plots showed the consequence of RNA and protein levels on clinical survival

involvement with the P13K/Akt and MAP/ERK pathways [27]. The GLi and SHH are part of the hedgehog signaling pathway that plays an essential role in the differentiation, growth, tissue patterning and cell maintenance of various cancers. However, its role in the CRC is still controversial [32]. PTCH1 is a tumor suppressor gene and its downregulation causes the activation of GLi transcription factors that activate the hedgehog target genes. CXCL14 is another potential tumor inhibiting gene in colorectal carcinoma and downregulation of this gene may result in a more aggressive phenotype of colorectal cancer [30]. Another prognostic biomarker of colorectal cancer is the TNFAIP3 which may also act as the tumor suppressor gene [33].

The network analysis revealed that these biomarkers play an essential role in colorectal cancer and that the dysregulation of these genes may lead to the progression of cancer. Targeting these pathways and the genes involved in the signaling of these pathways may help in easing the therapeutic profiling of colorectal cancer. The CTNNB1 and NNMT are known targets of CRC and both genes are known to interact with the MAPK pathways in causing CRC. The integrated network-based analysis helped in identifying the interaction of these potential biomarkers with other target genes through different integrated pathways.

\section{Conclusion}

Advancement in the clinical therapy of diseases is still a requisite and to improve the diagnostic measures validated biomarkers can aid in the diagnosis. The microarray analysis has helped in several ways to identify the 
novel targets for targeted based therapies. This study reveals the essential biomarkers involved in CRC through a system biology approach. Seven essential biomarkers of CRC having functional relation with other important target proteins such as APC, MAPK and GLi and have found a significant association with CRC. The study might help in rapid risk assessment of colorectal cancer by providing the new insights in clinical practice utilizing the microarray gene expression analysis.

\section{Supplementary information}

Supplementary information accompanies this paper at https://doi. org/10.1186/s40709-020-00118-1.

Additional file 1: Table S1. The function summaryAffyRNAdeg of Bioconductor package produced a single summary-statistic for each array in the batch dataset.

Additional file 2: Table S2. List of databases, software, and tools used in this study.

Additional file 3: Table S3. Preliminary investigation of common and related differentially expressed genes of each microarray dataset.

\section{Acknowledgements}

Not applicable.

\section{Authors' contributions}

SA and SZ conceived and designed the study. RA and UI carried out the research work. HN and SZ provided guidance with study design. All authors contributed in manuscript writing and edition. $\mathrm{HN}$ and $\mathrm{SA}$ read and approved the final manuscript. All authors read and approved the final manuscript.

\section{Funding}

Not applicable.

\section{Availability of data and materials}

The data has been presented with the article.

Ethics approval and consent to participate

Not applicable.

\section{Consent of publication}

Not applicable.

\section{Competing interests}

The authors declare that they have no competing interests.

\section{Author details}

${ }^{1}$ Department of Pharmaceutics, Faculty of Pharmaceutical Sciences, Riphah International University, Islamabad 44000, Pakistan. ${ }^{2}$ Department of Pharmaceutical Chemistry, Faculty of Pharmaceutical Sciences, Riphah International University, Islamabad 44000, Pakistan. ${ }^{3}$ Institute of Molecular Biology and Biotechnology, Bahauddin Zakariya University, Multan 66000, Pakistan.

Received: 27 April 2019 Accepted: 25 May 2020

Published online: 08 June 2020

\section{References}

1. Favoriti P, Carbone G, Greco M, Pirozzi F, Pirozzi RE, Corcione F. Worldwide burden of colorectal cancer: a review. Updates Surg. 2016;68(1):7-11.

2. Arnold M, Sierra MS, Laversanne M, Soerjomataram I, Jemal A, Bray F. Global patterns and trends in colorectal cancer incidence and mortality. Gut. 2017;66(4):683-91.
3. Palaghia M. Metastatic colorectal cancer: review of diagnosis and treatment options. Jurnalul de Chirurgie. 2015;10(4).

4. De Rosa M, Pace U, Rega D, Costabile V, Duraturo F, Izzo P, et al. Genetics, diagnosis and management of colorectal cancer (Review). Oncol Rep. 2015;34(3):1087-96.

5. Nannini M, Pantaleo MA, Maleddu A, Astolfi A, Formica S, Biasco G. Gene expression profiling in colorectal cancer using microarray technologies: results and perspectives. Caner Treat Rev. 2009;35(3):201-9.

6. Chou H-L, Yao C-T, Su S-L, Lee C-Y, Hu K-Y, Terng H-J, et al. Gene expression profiling of breast cancer survivability by pooled CDNA microarray analysis using logistic regression, artificial neural networks and decision trees. BMC Bioinform. 2013;14(1):100.

7. Chu CM, Yao CT, Chang YT, Chou HL, Chou YC, Chen KH, et al. Gene expression profiling of colorectal tumors and normal mucosa by microarrays meta-analysis using prediction analysis of microarray, artificial neural network, classification, and regression trees. Dis Markers. 2014. https:// doi.org/10.1155/2014/634123.

8. Chu C-M, Chen C-J, Chan D-C, Wu H-S, Liu Y-C, Shen C-Y, et al. CDH1 polymorphisms and haplotypes in sporadic diffuse and intestinal gastric cancer: a case-control study based on direct sequencing analysis. World J Surg Oncol. 2014;12(1):80.

9. Troyanskaya O, Cantor M, Sherlock G, Brown P, Hastie T, Tibshirani R, et al. Missing value estimation methods for DNA microarrays. Bioinformatics. 2001;17(6):520-5.

10. Bolstad BM, Irizarry RA, Åstrand M, Speed TP. A comparison of normalization methods for high density oligonucleotide array data based on variance and bias. Bioinformatics. 2003;19(2):185-93.

11. Fujita A, Sato JR, de Oliveira Rodrigues L, Ferreira CE, Sogayar MC. Evaluating different methods of microarray data normalization. BMC Bioinform. 2006;7(1):469.

12. Obenchain V, Lawrence M, Carey V, Gogarten S, Shannon P, Morgan M. Variantannotation: a bioconductor package for exploration and annotation of genetic variants. Bioinformatics. 2014;30(14):2076.

13. Jin Y, Da W. Retracted Article: screening of key genes in gastric cancer with DNA microarray analysis. Eur J Med Res. 2013;18(1):37.

14. Eisen MB, Spellman PT, Brown PO, Botstein D. Cluster analysis and display of genome-wide expression patterns. Proc Natl Acad Sci. 1998;95(25):14863-8.

15. Scherf U, Ross DT, Waltham M, Smith LH, Lee JK, Tanabe L, et al. A gene expression database for the molecular pharmacology of cancer. Nat Genet. 2000;24(3):236.

16. Nam D, Kim S-Y. Gene-set approach for expression pattern analysis. Brief Bioinform. 2008;9(3):189-97.

17. Muhammad SA, Ahmed S, Ali A, Huang H, Wu X, Yang XF, et al. Prioritizing drug targets in Clostridium botulinum with a computational systems biology approach. Genomics. 2014;104(1):24-35.

18. Huang DW, Sherman BT, Tan Q, Kir J, Liu D, Bryant D, et al. DAVID Bioinformatics Resources: expanded annotation database and novel algorithms to better extract biology from large gene lists. Nucleic Acids Res. 2007;35((suppl_2)):W169-75.

19. Pathan M, Keerthikumar S, Ang CS, Gangoda L, Quek CY, Williamson NA et al. FunRich: an open access standalone functional enrichment and interaction network analysis tool. Proteomics. 2015;15(15):2597-601.

20. Rachlin J, Cohen DD, Cantor C, Kasif S. Biological context networks: a mosaic view of the interactome. Mol Syst Biol. 2006;2(1):66.

21. Szklarczyk D, Franceschini A, Kuhn M, Simonovic M, Roth A, Minguez $P$, et al. The STRING database in 2011: functional interaction networks of proteins, globally integrated and scored. Nucleic Acids Res. 2011;39:D561-8.

22. Chen JY, Mamidipalli S, Huan T. HAPPI: an online database of comprehensive human annotated and predicted protein interactions. BMC Genomics. 2009;10(1):S16.

23. Cline MS, Smoot M, Cerami E, Kuchinsky A, Landys N, Workman C, et al. Integration of biological networks and gene expression data using cytoscape. Nat Protoc. 2007;2(10):2366.

24. Shannon P, Markiel A, Ozier O, Baliga NS, Wang JT, Ramage D, et al. Cytoscape: a software environment for integrated models of biomolecular interaction networks. Genome Res. 2003;13(11):2498-504.

25. Kanehisa M, Goto S. KEGG: kyoto encyclopedia of genes and genomes. Nucleic Acids Res. 2000;28(1):27-30 
26. Kutmon M, van lersel MP, Bohler A, Kelder T, Nunes N, Pico AR, et al. PathVisio 3: an extendable pathway analysis toolbox. PLoS Comput Biol. 2015;11(2):e1004085.

27. Xie X, Yu H, Wang Y, Zhou Y, Li G, Ruan Z, et al. Nicotinamide N-methyltransferase enhances the capacity of tumorigenesis associated with the promotion of cell cycle progression in human colorectal cancer cells. Arch Biochem Biophys. 2014;564:52-66.

28. Wang HL, Hart J, Fan L, Mustafi R, Bissonnette M. Upregulation of glycogen synthase kinase 3 beta in human colorectal adenocarcinomas correlates with accumulation of CTNNB1. Clin colorectal Cancer. 2011;10(1):30-6.

29. Gerling M, Büller NV, Kirn LM, Joost S, Frings O, Englert B, et al. Stromal Hedgehog signalling is downregulated in colon cancer and its restoration restrains tumour growth. Nat Commun. 2016;7:12321.

30. Lin K, Zou R, Lin F, Zheng S, Shen X, Xue X. Expression and effect of CXCL14 in colorectal carcinoma. Mol Med Rep. 2014;10(3):1561-8.

31. Jeong WJ, Ro EJ, Choi KY. Interaction between Wnt/beta-catenin and RAS-ERK pathways and an anti-cancer strategy via degradations of beta-catenin and RAS by targeting the Wnt/beta-catenin pathway. NPJ Precision Oncol. 2018;2(1):5.

32. Wu C, Zhu X, Liu W, Ruan T, Tao K. Hedgehog signaling pathway in colorectal cancer: function, mechanism, and therapy. OncoTargets Ther. 2017; 10:3249-59.

33. Ungerbäck J, Belenki D, Jawad ul-Hassan A, Fredrikson M, Fransén K, Elander $N$, et al. Genetic variation and alterations of genes involved in NFKB/TNFAIP3-and NLRP3-inflammasome signaling affect susceptibility and outcome of colorectal cancer. Genetic Variation Carcinog. 2012;33(11):2126-34.

34. Selga E, Noé V, Ciudad CJ. Transcriptional regulation of aldo-keto reductase 1C1 in HT29 human colon cancer cells resistant to methotrexate: Role in the cell cycle and apoptosis. Biochem Pharmacol. 2008;75(2):414-26.

35. Mencia N, Selga E, Noé V, Ciudad CJ. Underexpression of miR-224 in methotrexate resistant human colon cancer cells. Biochem Pharmacol. 2011;82(11):1572-82.
36. Hwang $W-L$, Yang M-H, Tsai M-L, Lan H-Y, Su S-H, Chang S-C, Teng H-W, Yang S-H, Lan Y-T, Chiou S-H, Wang H-W. SNAIL regulates interleukin-8 expression, stem cell-like activity, and tumorigenicity of human colorectal carcinoma cells. Gastroenterology. 2011;141(1):279-91.e5.

37. Sagiv E, Starr A, Rozovski U, Khosravi R, Altevogt P, Wang T, Arber N. Targeting CD24 for treatment of colorectal and pancreatic cancer by monoclonal antibodies or small interfering RNA. Cancer Res. 2008;68 (8):2803-12.

38. Katkoori VR, Shanmugam C, Jia X, Vitta SP, Sthanam M, Callens T, Messiaen L, Chen D, Zhang B, Bumpers HL, Samuel T, Manne M, Jagetia GC. Prognostic significance and gene expression profiles of p53 mutations in microsatellite-stable stage III colorectal adenocarcinomas. PLoS ONE. 2012;7(1):e30020.

39. Chen W, Tang T, Eastham-Anderson J, Dunlap D, Alicke B, Nannini M, Gould S, Yauch R, Modrusan Z, DuPree KJ, Darbonne WC, Plowman G, de Sauvage FJ, Callahan CA. Canonical hedgehog signaling augments tumor angiogenesis by induction of VEGF-A in stromal perivascular cells. Proc Nat Acad Sci. 2011;108(23):9589-94.

40. Khamas A, Ishikawa T, Shimokawa K, Mogushi K, lida S, Ishiguro M, et al. Screening for epigenetically masked genes in colorectal cancer using 5-Aza-2'-deoxycytidine, microarray and gene expression profile. Cancer Genomics Proteomics. 2012;9(2):67-75.

41. Uronis JM, Osada T, McCall S, Yang XY, Mantyh C, Morse MA, Kim Lyerly $\mathrm{H}$, Clary BM, Hsu DS, Welm AL. Histological and molecular evaluation of patient-derived colorectal cancer explants. PLoS ONE. 2012;7(6):e38422.

42. Schoumacher M, Hurov KE, Lehar J, Yan-Neale Y, Mishina Y, Sonkin D, Korn JM, Flemming D, Jones MD, Antonakos B, Cooke VG, Steiger J, Ledell J, Stump MD, Sellers WR, Danial NN, Shao W. Inhibiting tankyrases sensitizes KRAS-mutant cancer cells to MEK inhibitors via FGFR2 feedback signaling. Cancer Res. 2014;74(12):3294-305.

\section{Publisher's Note}

Springer Nature remains neutral with regard to jurisdictional claims in published maps and institutional affiliations.
Ready to submit your research? Choose BMC and benefit from:

- fast, convenient online submission

- thorough peer review by experienced researchers in your field

- rapid publication on acceptance

- support for research data, including large and complex data types

- gold Open Access which fosters wider collaboration and increased citations

- maximum visibility for your research: over $100 \mathrm{M}$ website views per year

At BMC, research is always in progress.

Learn more biomedcentral.com/submissions 